\title{
A new meeting of pneumology residents in sibiu
}

Florin Mihălţan ${ }^{\dagger}$

Marius Nasta Institute of Pneumoftiziology Institute, Bucharest, Romania

With the coming of winter and December, SIBIU received with open arms the 45 residents who obtained the right to participate in the 8th Conference of Pneumological Resident Physician. Scheduled between14th-15th December 2018, the conference was opened by a session of the seniors doctors that raised the appetite for sciencewhere there were reviewed current problems of Romanian and international pneumology.

Topics such as "Pollution: how does it affect breathing?" (Ruxandra Ulmeanu), "How to write a scientific article" (Alina Croitoru), "Residents and their problems" (Florin Mihălţan), "Practical aspects regarding interpretation of respiratory functional tests and computed tomographies" (Dragoş Zaharia), "Pulmonary hypertension - a multidisciplinary approach" (Nicoleta Bertici), "Idiopathic pulmonary fibrosis diagnostic and treatment elements" (Claudia Toma), "Pleurisy diagnosis: a continuous challenge in medical practice" (Petronela Fildan), "What ACO means (asthma-COPD overlap) in 2018?" (Ruxandra Râjnoveanu) and "Influence of smoking on the evolution of bronchial asthma" (Corina Mărginean) were discussed.

The second day was fully allocated to residents' presentations. For the first time in the history of these traditional meeting ending the calendar year of the Romanian Society of Pneumology, the number of young hopes reached 45.

Exposures were staggered in four sessions: "Diffuse Interstitial Pneumopathies", "Tuberculosis: Confirmations of Diagnosis and Surprises", "Obstructive Diseases" and "Respiratory Infections, Tumor Pathology and Systemic diseases". In the morning, all the participants lived through the excitement of their debut during the show, surpassed the emotions of public appearance and we assisted to presentations, proving in many cases a maturity of analyzing and artistically dressing the exposure of the cases or studies enrolled in the contest.

Clinical cases prevailed as in other years, with various forms of tuberculosis associated with various comorbidities, atypical forms of neoplasia, systemic diseases or expressions of diffuse interstitial pneumonitis. Much more rarely have been research in patient groups that once again prove the immense scientific reservoir that can be speculated by the younger future pneumologist for the next national or international sessions where they could participate.

The quality of scientific exposure and "artistic" performance of the presenter was appreciates by ratings given by both senior and junior colleagues. The first prize was obtained by loana Sânziana Husaru, the second prize by Marius Sava and the third prize by Dragos Băiceanu. There were also three mentions for Ioana Ilca, Lorena Sabadoş and Stefan Cosmin Tiplea. A special prize was given by a jury to a representative of the Republic of Moldova: Denis Ardeleanu. In fact, this conference has always enjoyed the presence of a delegation of four colleagues from the Republic of Moldova and a Bulgarian resident working in Romania.

It was a new experience of a promising generation of residents. The enthusiasm of the participants was and remains an additional motivation for the continuation of this type of meeting sponsored by the Romanian Society of Pneumology. 